\title{
O dispositivo da sustentabilidade: pedagogias no contemporâneo
}

\author{
Shaula Maíra Vicentini de Sampaio* \\ Leandro Belinaso Guimarães ${ }^{* *}$
}

\begin{abstract}
Resumo
O presente trabalho deriva-se de duas pesquisas, cujo foco central é a relação entre a educação e a sustentabilidade. Discutem-se no texto as pedagogias postas em circulação na cultura a partir do dispositivo da sustentabilidade, através dos seus inúmeros artefatos (textos jornalísticos, capas de revistas, entre outros). Inicialmente, explicita-se o entendimento do conceito de dispositivo: noçáo com a qual se operam as análises das pesquisas. Depois, adentra-se nas pedagogias instituídas pelas linhas de composição do dispositivo da sustentabilidade através de duas imagens midiáticas sobre a questấo ambiental. A partir delas, argumenta-se um dos efeitos pedagógicos do dispositivo: sua penetrabilidade, pelas teias do mercado, nos modos como se enxerga e se narra a vida. Os referenciais teóricos utilizados advêm dos Estudos Culturais, em suas vertentes pós-estruturalistas. Esse amplo e controverso campo de estudos e de práticas permite colocar sob rasura as narrativas sobre a sustentabilidade, buscando vê-las em seus efeitos.
\end{abstract}

Palavras-chave: Sustentabilidade. Educação Ambiental. Educação pela Mídia.

\footnotetext{
* Doutora em Educação pela Universidade Federal do Rio Grande do Sul (UFRGS). Professora do curso de Ciências Biológicas da Universidade Federal de Alagoas (UFAL).

** Doutor em Educação pela Universidade Federal do Rio Grande do Sul (UFRGS). Professor do Programa de Pós-Graduação em Educação (PPGE) da Universidade Federal de Santa Catarina (UFSC).
} 
Em uma sala de aula, alunos sentados em pequenos grupos executam uma tarefa encaminhada pelo professor. A tarefa era montar, inventivamente, uma reportagem jornalística sobre "sustentabilidade". Esse era o primeiro ato daquela prática pedagógica que estava começando. Antes mesmo de o professor comunicar os prováveis objetivos pedagógicos daquela prática, a tarefa precisava ser cumprida! Qual seria a imagem que acompanharia a reportagem de cada grupo? Qual legenda estaria estampada sob ela? Qual o título da notícia? Em que seção do jornal ela estaria disposta? O que ela narraria? Essas eram algumas das questôes, propostas pelo professor, que circulavam pelos grupos no momento de manipulaçáo e compartilhamento das ideias para a montagem das reportagens.

Várias foram as notícias criadas em práticas pedagógicas semelhantes executadas pelo professor com diferentes públicos (jovens, professores em formação inicial ou continuada). É impossível enfocar, nesta introdução, todas as reportagens imaginadas e criadas. Portanto, escolhemos três delas: as que mais se articulam com os argumentos tecidos ao longo do texto. Náo importa, ao menos para este trabalho, quem era o grupo de alunos que escreveu cada notícia comentada. Para nós, o que interessa aqui são as narrativas que emergiram, brotaram, se processaram na atividade. Como veremos mais adiante, nelas atuam incisivamente algumas das linhas de força do que estamos chamando de dispositivo da sustentabilidade. Fios cortantes e suaves que nos atravessam, que nos tomam, nos provocam, nos acolhem, que nos tocam e nos acomodam, que nos agridem e nos enredam no tempo presente.

Em uma das reportagens construídas, o título inventado foi: "O uso econômico e sustentável da taboa". As fibras desse vegetal incomum geravam trabalho e renda para mulheres de uma comunidade interiorana do Brasil, dizia a criativa notícia. Na imagem desenhada que acompanhava o texto, uma luminária feita das fibras da taboa reluzia sobre a legenda, que reforçava o efeito decorativo do objeto (quem resistiria a consumir um artefato com tantos benefícios, se não estéticos, ao menos ambientais e sociais?).

Uma segunda reportagem trazia em letras garrafais o título: "Arquitetura sustentável: como viver sem causar impactos ambientais". Frase grafada na própria imagem em que uma árvore se travestia de edifício. A legenda náo poderia ser mais explicativa: imagem idealizada (não seria interessante nossos apartamentos transmitirem a sensaçáo de que moramos junto à natureza?) da nova tendência da arquitetura mundial (a sustentabilidade teria um apelo planetário?).

PERSPECTIVA, Florianópolis, v. 30, n. 2, 395-409, maio/ago. 2012

http://www.perspectiva.ufsc.br 
Quase como um contraponto às duas reportagens acima, um grupo inventou uma notícia repleta de contestação, de indignação. O título denunciava: "O marketing da sustentabilidade: [...] você é um consumidor influenciado?". A reportagem dizia que as empresas não cumpriam com as premissas da sustentabilidade, mas os consumidores compravam seus produtos ludibriados pela publicidade, que atestava seus atributos "verdes". A imagem era composta por um consumidor sorridente escolhendo na gôndola do supermercado um produto que seria aparentemente sustentável. Seu pensamento podia ser lido no balão (tal qual vemos nas histórias em quadrinhos) que anunciava sua preocupaçáo "verde". Aqui a questáo náo foi tecer um contraponto à ideia de sustentabilidade em si mesma, mas, somente, exigir sua efetiva presença nos processos empresariais, sobretudo publicitários. E mais, a reportagem criada desejou um consumidor mais esclarecido quanto ao caráter sustentável dos produtos que compra (alguém poderia ser contrário a tal pedagogia?).

Nestas três pequenas "reportagens", temos um pouco da rede que se costura no contemporâneo a partir daquilo que nomeamos como as linhas de composiçâa do dispositivo da sustentabilidade. Aliam-se a esse intricado emaranhado diferentes sujeitos: mulheres trabalhadoras, arquitetos antenados com o novo tempo, consumidores entorpecidos com tanta publicidade, nós mesmos: autores e leitores deste texto.

No entorno da sustentabilidade, parecem gravitar discursos em disputa. Contudo, tal como aponta Henri Acselrad (1999) em um artigo sobre o tema, são os discursos econômicos os que mais intensamente se apropriam desta noção e a disseminam pelas sociedades. Diante disso, o desafio à Educação Ambiental parece ser a articulação de dispositivos outros, através dos quais se possam proliferar práticas não mercantis no cotidiano das nossas vidas (nem que para isso seja preciso rasgar a própria noção de sustentabilidade). Voltaremos a esse ponto na seção final do texto. Passamos agora a marcar como vislumbramos a construção do nosso artigo.

Neste trabalho - proveniente de duas pesquisas interessadas na relação entre educação e sustentabilidade -, anunciamos, primeiramente, o que temos entendido pelo conceito de dispositivo. Depois, adentramos nas pedagogias derivadas das linhas de composição do dispositivo da sustentabilidade e percorremos duas de suas inúmeras imagens, mostrando, sobretudo, um de seus efeitos mais estonteantes sobre nós: sua penetrabilidade, pelas teias do mercado, nos modos como vemos e narramos a vida. Por fim, tecemos, brevemente, 
alguns comentários sobre como podemos pensar, nos trabalhos de Educação Ambiental em que estamos envolvidos, práticas de resistência a esse dispositivo, pois, como argumenta Raymond Williams, "[...] uma cultura viva não pode, em momento algum, reduzir-se aos seus artefatos" (WILLIAMS, 1969, p. 332).

Nossos referenciais teóricos advêm dos Estudos Culturais, em suas vertentes pós-estruturalistas. É esse amplo, contestado e controverso campo de estudos e de práticas que nos permite estranhar, colocar sob rasura - para usar um termo cunhado em um importante e já clássico ensaio de Stuart Hall (1997) - as narrativas sobre a sustentabilidade, buscando vê-las em seus efeitos pedagógicos sobre nós mesmos. Pois, como aponta Carlos Eduardo Ferraço (2007), pesquisamos sobre nós mesmos, somos nossos próprios temas de investigação quando enfocamos, em nossos trabalhos, o cotidiano que nos enreda, nos tece e nos costura.

\section{As tramas do dispositivo}

Desde o fim do século XX, estamos presenciando a configuração e a intensificação disso que estamos chamando de dispositivo da sustentabilidade, que tem se mostrado bastante ativo na nossa atualidade, interpelando-nos a partir de inúmeras instâncias. $\mathrm{O}$ uso que fazemos da noçáa de dispositivo remete às teorizaçóes de Michel Foucault, quando o autor enfoca o dispositivo da sexualidade, o dispositivo prisional, os dispositivos de segurança, entre outros. No texto intitulado Sobre a sexualidade, Foucault disse estar referindose, com a noção de dispositivo, a um conjunto heterogêneo "[...] que engloba discursos, instituiçôes, organizaçóes arquitetônicas, decisóes regulamentares, leis, medidas administrativas, enunciados científicos, proposiçôes filosóficas, morais, filantrópicas" (FOUCAULT, 2003, p. 244). Ele acrescenta ainda que o dispositivo se constitui a partir de uma rede (nunca pronta ou estável) entre o dito e o náo dito. Para Foucault (2003), todo dispositivo tem a função principal de responder a uma urgência e, por isso, possui um papel estratégico crucial na produção das verdades que predominam em determinados tempos históricos. Nas palavras do filósofo, um dispositivo é basicamente constituído por "[...] estratégias de relaçóes de força sustentando tipos de saber e sendo sustentadas por eles" (FOUCAULT, 2003, p. 246).

Também é interessante indicar outros desdobramentos que se dão a partir desse conceito quando acionado por outros pensadores. Destacamos 
especialmente a leitura feita por Deleuze (1999). O filósofo enfatiza uma dimensão mais topológica do dispositivo, na medida em que o define como um conjunto multilinear composto por linhas ou vetores que algumas vezes se aproximam e, outras vezes, se afastam uns dos outros. Isto é, os componentes de um dispositivo não detêm um significado intrínseco, mas adquirem-no mediante a distância que possuem entre si, as funçóes que exercem no dispositivo e, ainda, na relação que travam uns com os outros. Além disso, Deleuze (1999) ressalta que algumas linhas do dispositivo atuam na sua sedimentação (estabilização), enquanto outras linhas podem promover rupturas e transformaçôes e, até mesmo, a extinçáo do dispositivo.

Ainda de acordo com Deleuze (1999), o dispositivo é composto por linhas de diferentes naturezas, que se distinguem em suas dimensóes e se articulam aos três grandes eixos desenvolvidos por Foucault em sua obra: o saber, o poder e a subjetivação. Essas dimensões são designadas como linhas de visibilidade e de enunciação, linhas de força, linhas de subjetivação e, por fim, linhas de fratura, pois qualquer linha pode ser rompida ou dar origem a outra. Como a distinção entre tais linhas será útil para caracterizarmos o que estamos entendendo por dispositivo da sustentabilidade, vale mostrar brevemente como Deleuze (1999) apresenta esta trama disforme que compóe os dispositivos e a relação que nós tecemos com ela.

As linhas de visibilidade conformam o visível de formas particulares, inseparáveis deste ou daquele dispositivo, pois "[...] cada dispositivo tem seu regime de luz, a maneira pela qual a luz cai, se esfuma, se expande, distribuindo o visível e o invisível, fazendo nascer ou desaparecer um objeto que não existe sem ela" (DELEUZE, 1999, p. 155). A segunda dimensão do dispositivo, mencionada por Deleuze (1999), é composta pelas curvas de enunciação. Marcello (2004) destaca que os regimes de enunciação não se referem somente àquilo que se fala sobre algo, mas sim àquilo que torna possível e justificável falar sobre determinada coisa. É importante realçar que a relação entre o visível e o enunciável não se constitui como uma relação necessária, obrigatória ou indissociável, pois está "[...] muito mais no âmbito da articulação e da complementaridade" (MARCELLO, 2009, p. 233). Tal articulação se processa de forma que as linhas de visibilidade e enunciaçáo, ao capturarem os sujeitos, fazendo-os visíveis e enunciáveis de modos específicos e diferenciados, tornam eficazes os agenciamentos concretos aos quais se destina o dispositivo (MARCELLO, 2004). 
Deleuze (1999) destaca também a importante atuação das linhas de força, as quais se produzem em toda relação de um ponto com o outro, passando por todos os pontos do dispositivo. "Essas linhas se compóem, tal como o poder, em relação ao saber: não como causa e consequência, mas através de uma relação de mútua dependência, de articulação recíproca" (MARCELLO, 2004, p. 204). Como aponta Veiga-Neto (2005), o poder e o saber se entrecruzam no sujeito, que é seu produto concreto. E, nesse ponto, podemos adentrar no próximo atravessamento do dispositivo mencionado por Deleuze: as linhas de subjetivação. Essas exprimem os processos de subjetivação que estão, necessariamente, implicados no dispositivo. A partir da modulaçấo com as demais linhas do dispositivo, exploradas anteriormente, as linhas de subjetivação seriam as responsáveis pelos "[...] contínuos convites para que o sujeito entre em relação de força consigo mesmo" (MARCELLO, 2005, p. 139).

Como explica Marcello, "[...] a relaçáo consigo náo é mais da ordem do visível e do enunciável, nem da sistematização das forças - embora derive deles, ela é irredutível a eles. Ela passa a ser luta agonística do sujeito consigo mesmo para a produçáo de si” (MARCELLO, 2009, p. 234). Essa linha escapa às anteriores, podendo tornar-se uma linha de fuga (DELEUZE, 1999). Ou seja, esse processo torna possível a criaçáo de espaços onde aconteçam possíveis fugas e subversóes do próprio modo como o dispositivo delimita o sujeito. Segundo Deleuze (1999), as linhas de subjetivaçáo podem ser pensadas como o limite extremo do dispositivo, esboçando a passagem de um dispositivo para outro. Tais linhas podem engendrar linhas de fratura, de fissura, no dispositivo, produzindo "[...] novas configuraçóes de saber-podersubjetividade, e por isso podem suscitar e antecipar um dispositivo futuro" (MARCELLO, 2009, p. 234). Não há, portanto, uma configuração estável, definitiva, que o dispositivo assumiria. Ao contrário, este se caracteriza por sua contínua possibilidade de se recompor e ou se transmutar, originando um novo dispositivo. Dessa maneira,

[...] todo dispositivo se define assim por seu teor de novidade e criatividade, que marca ao mesmo tempo sua capacidade de se transformar, ou de se cindir em proveito de um dispositivo futuro, ou ao contrário, de fortificarse sobre suas linhas mais duras, mais rígidas ou sólidas. (DELEUZE, 1999, p. 159). 
Podemos dizer, então, que os dispositivos que coexistem em determinado período histórico conformam e modulam as formas de pensar, perceber e sentir o mundo em dado momento. A subjetividade contemporânea é, assim, engendrada pelos dispositivos que atuam na promoçáo de visibilidades e enunciações que definem como nos constituímos, como nos vemos e nos narramos. "Nós pertencemos a dispositivos e agimos neles. A novidade de um dispositivo em relaçáo aos precedentes pode ser chamada de sua atualidade, nossa atualidade" (DELEUZE, 1999, p. 159). Por esse motivo, consideramos extremamente oportuno focalizar, problematizar e pensar o dispositivo da sustentabilidade, que está fortemente implicado (em articulaçấo com outros dispositivos) nos modos contemporâneos de compreender o mundo e a nós mesmos. Este dispositivo está em plena atividade, produzindo-nos continuamente por meio da constituiçáo de domínios de saber (por meio de linhas de visibilidade e de enunciação), de relaçôes de poder (linhas de força) e, desse modo, subjetivando-nos e enredando-nos em suas linhas. Pertencemos a ele e agimos nele todos os dias, seja no momento em que abrimos uma revista ou jornal (na próxima seção, focaremos duas de suas imagens veiculadas nesses artefatos), seja quando ligamos a televisão, quando frequentamos nossos locais de trabalho, quando conversamos com nossos amigos, quando viajamos... Enfim, com seus tentáculos (ou linhas), o dispositivo da sustentabilidade nos atravessa por meio das suas múltiplas estratégias, instando-nos a falar sua língua, a moldar nossas atitudes em conformidade com seus discursos.

\section{Um dispositivo insinuante ensina que dinheiro brota em árvores}

De acordo com Deleuze (1999), é importante lembrar que todas as linhas dos dispositivos são linhas de variação, que não possuem coordenadas constantes. Portanto, uma tentativa de mapeamento do dispositivo da sustentabilidade não garantiria a existência de uma forma prévia, dada e sedimentada que poderia ser assumida por tal dispositivo, visto que há sempre a possibilidade de nele ocorrerem tensionamentos e, até, cisóes. Como resume Marcello (2004), o dispositivo tem necessidade de refazer-se e de fazer produzir incessantemente, sendo possível dizer que essa mobilidade se dá a ver nos modos como a sustentabilidade foi sendo apropriada e remanejada a partir da sua conexão 
com outras práticas econômicas e políticas, produzindo, assim, novos discursos, estes mais afinados com os interesses do capital.

Como vimos na seção anterior, os dispositivos atuam de forma ativa na fabricação dos sujeitos (MARCELLO, 2005). Por isso, caberia perguntar: como os sujeitos aprendem a se ver e a se narrar a partir do dispositivo da sustentabilidade? Em outro texto, a autora indica que "[...] o dispositivo da infantilidade precisa infantilizar seus sujeitos, da mesma forma que o dispositivo da maternidade necessita maternizar os seus" (MARCELLO, 2009, p. 236). Seguindo essa pista, poderíamos conjeturar que o dispositivo da sustentabilidade precisa "esverdear" seus sujeitos. Isso significa dizer que ver a sustentabilidade como um dispositivo demanda a produção de um tipo de sujeito disposto a mudar seus hábitos de vida, além de ser sensível aos apelos ligados à promoção da sustentabilidade, pois ser "verde", hoje, é estar ligado ao seu tempo. Entretanto, mais do que a produção de uma subjetividade "verde", o que está também em jogo é a conexão indelével, arrebatadora, desse humano às prerrogativas de um mercado que está se revitalizando, se renovando, se expandindo lucrativamente, como "verde".

Esse sujeito "verde" seria, então, aquele que é objetivado pelas linhas de enunciação e de visibilidade (sempre em modulação com as linhas de força) do dispositivo da sustentabilidade. Este sujeito é atravessado por uma profusão de imagens que conformam a necessidade de um mundo mais "verde", mais sustentável - tanto aquelas imagens catastróficas (de florestas em chamas, de geleiras definhando) quanto aquelas "positivas" de experiências sustentáveis tidas como bem-sucedidas. Tal sujeito é, também, interpelado pelos mais diferentes discursos sobre sustentabilidade: os discursos legais, institucionais, governamentais, midiáticos, escolares, dos movimentos sociais. Nos entrelaçamentos entre o visível e o enunciável, produzem-se os agenciamentos das subjetividades pelo dispositivo da sustentabilidade. Estes agenciamentos afetam a todos, sejamos crianças, sejamos homens, mulheres, ricos, pobres... Assim, como diz Redclift, "[...] no século XXI, faz sentido considerar-nos como parte do discurso da sustentabilidade" (REDCLIFT, 2006, p. 71, tradução nossa).

Essa pedagogia exercida pelo dispositivo da sustentabilidade se processa em instâncias múltiplas sobre as quais o dispositivo se aplica, ultrapassando as fronteiras das instituiçôes escolares e mesmo das ações de Educação Ambiental. Aprendemos a ser - verdes - nos mais diversos âmbitos, mas convém realçar o papel incisivo da mídia neste processo. Para Fischer (2002), podemos falar, 
inclusive, em um - dispositivo pedagógico da mídia -, se considerarmos os modos pelos quais ela participa efetivamente da constituição dos sujeitos e das subjetividades, produzindo saberes que de alguma forma se voltam à - educação - das pessoas, ensinando-lhes a ser e estar na cultura em que vivem.

Desse modo, assistimos a uma proliferação de artefatos culturais que nos colocam diariamente em contato com o dispositivo da sustentabilidade. Um mundo mais "verde" e sustentável parece estar apenas começando, e para ele um novo sujeito é necessário. Para esse mundo e esse novo consumidor "verde", um conjunto amplo de objetos e serviços está sendo criado. Evidenciase assim o quanto o dispositivo da sustentabilidade, através das suas linhas de subjetivação, conforma modos de existir na contemporaneidade, atuando na produção de sujeitos preocupados com a sobrevivência do planeta e, portanto, engajados na fabricação deste "mundo mais verde" por meio de ações cotidianas - especialmente quando consideramos aquelas ligadas ao consumo. Ingressar e participar dessas redes de significado na atualidade tornou-se algo náo somente desejável, uma vez que representa a contribuição de cada um para um "planeta melhor", mas também socialmente prestigiado, pois se constitui num ethos reconhecido e valorizado.

A seguir, destacamos duas imagens engendradas no entrelaçamento das linhas que constituem o dispositivo da sustentabilidade. Como dissemos na introdução deste trabalho, após demarcarmos o conceito de dispositivo, apresentaríamos o caráter pedagógico do dispositivo da sustentabilidade, destacando uma de suas mais avassaladoras características: sua penetrabilidade nas práticas culturais e subjetivas do tempo presente. Muitas são as imagens forjadas por esse dispositivo, mas essas duas fazem notar um dos seus aspectos incisivos que recai sobre nós mesmos: a monetarização da nossa própria vida.

Ambas as imagens são capas, respectivamente, de um caderno jornalístico mensal focado em sustentabilidade e de uma revista, também mensal, endereçada a leitores interessados em economia e negócios. A capa desta última destaca um número cuja reportagem principal trata de sustentabilidade. Os textos escritos pouco nos interessam. Desejamos atentar para as imagens que compóem as capas. Nelas, uma árvore e uma flor são tecidas, corporificadas, coloridas por cédulas e moedas de dinheiro.

A vida parece brotar em dinheiro. Práticas sustentáveis estáo acondicionadas em uma estética que nos força a ver a vida por seu reluzente, convidativo e assustador valor monetário. Flores emanam odores de papel- 
moeda. Árvores se tornam multicoloridas, eternamente vivas, com suas folhas de cédulas de dinheiro. Imagens-símbolo da penetrabilidade do mercado, do capital, no próprio tecido dos seres vivos, que deixou, definitivamente, de ser apenas orgânico.

Figura 1 - Sustentabilidade na mídia Figura 2 - Sustentabilidade na Mídia
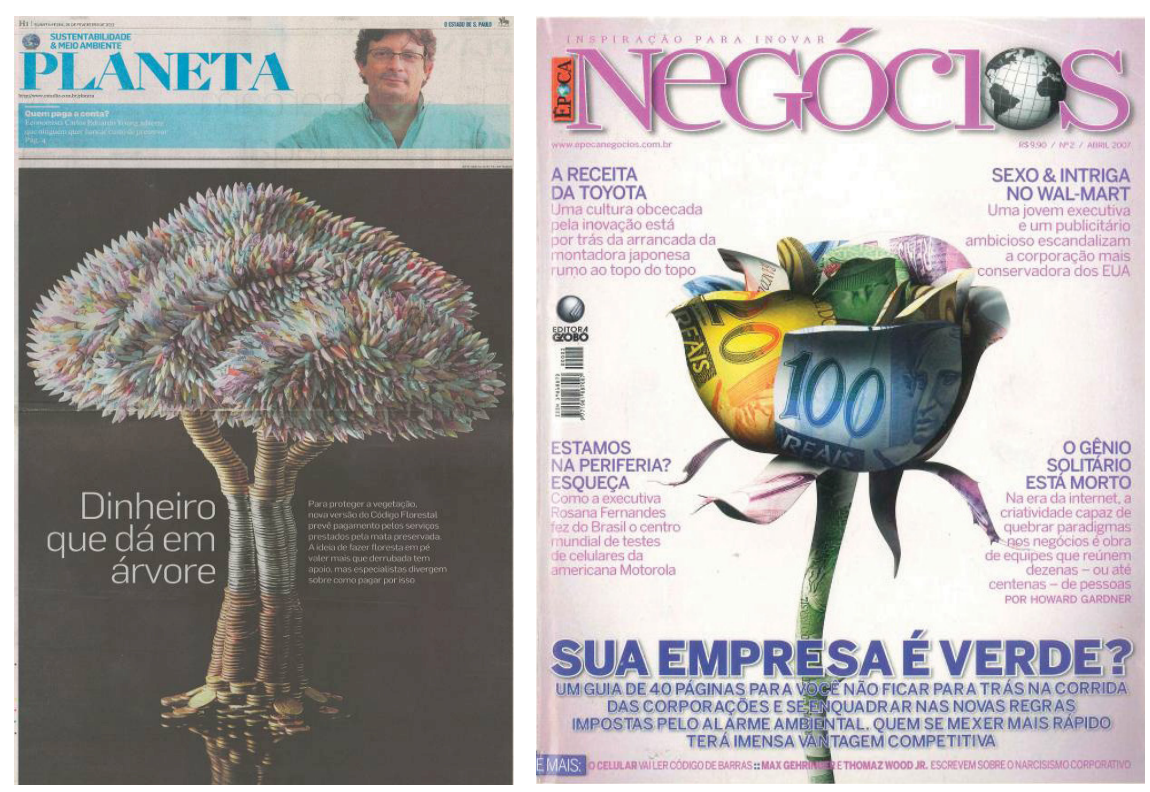

Fonte: Suplemento mensal Planeta. O Estado Fonte: Revista Época Negócios, n. 2, abril de 2007. de São Paulo, 29 de fevereiro de 2012.-

E não são apenas árvores e flores que se vestem de dinheiro, somos nós mesmos incorporados nas linhas de um dispositivo que visa a tornar sustentáveis, "verdes", lucrativas e econômicas não apenas nossas práticas cotidianas, mas nossos próprios corpos, nossos odores, nossas cores, nossas relaçóes, nossas vidas.

\section{Nas fissuras do dispositivo: qual Educação Ambiental?}

Como argumenta Marcello (2009), retomando as proposiçóes de Deleuze (1999) sobre o dispositivo, são as linhas de subjetividade que fazem com que o dispositivo nunca se torne um sistema rígido e fechado, permitindo a criação 
de espaços onde podem ocorrer fugas e subversōes no modo como o dispositivo delimita o sujeito. É interessante perceber que as próprias linhas que efetivam a produção de um determinado sujeito são aquelas que possibilitam novas produçôes, introduzindo a descontinuidade e a transformaçáo no seio do dispositivo. Nessa direção, "[...] a capacidade de promoção de linhas de fuga, de possibilidades de subversão e de produção de novas relaçôes de força são também operadas pelos próprios sujeitos em questáo" (MARCELLO, 2004, p. 210).

A instabilidade e a heterogeneidade características dos dispositivos possibilitam, justamente, sua renovação incessante, sua permanente atualização, pois eles necessitam de rearranjos constantes e nunca se estabilizam em uma forma definitiva. São os movimentos de resistência que geram as relações agonísticas entre modalidades subjetivas associadas a um dispositivo. É precisamente porque há resistência que o dispositivo precisa reafirmar continuamente sua validade e legitimidade, na busca ininterrupta por se manter, por continuar a existir. "A luta agonística é necessária aos movimentos não apenas de resistência, como de fuga, justamente porque é a partir dela que são promovidas novas formas de objetivação" (MARCELLO, 2009, p. 234). Por outro lado, a resistência nunca se dá como uma ruptura total das formas de subjetivação, mas permite novas configuraçôes dos regimes de saber-poder, acarretando novas formas de produção de sujeitos (MARCELLO, 2009). Conforme pontua Deleuze (1999), a produção de subjetividade escapa aos poderes e aos saberes de um dispositivo para entrar em relação com os poderes e os saberes de outro dispositivo que ainda está por aparecer.

Com base nestas consideraçóes, gostaríamos de indagar sobre as possibilidades de fuga, ruptura, subversão que podem se efetuar no que estamos definindo como o dispositivo da sustentabilidade. Por se tratar de um dispositivo recente, cujo emaranhado de linhas forma uma rede que apenas começamos a vislumbrar, vale perguntar: que outras modulaçôes podem derivar de suas linhas? Isto é, que outras imagens e enunciados podem ser produzidos sobre sustentabilidade nos nossos dias além destes que foram aqui expostos? Acreditamos ser necessário, inicialmente, discutir e desmanchar aspectos já naturalizados (porque exaustivamente enunciados) que integram este dispositivo, tentando promover fissuras em alguns consensos que, de tanto serem repetidos, nos chegam como verdades inquestionáveis.

Entretanto, para além das operaçóes de desmanche, acreditamos ser preciso entrever novas narrativas, novas imagens que possam liberar, neste dispositivo, a diferença, as linhas de invenção, de criação. Rastrear as forças 
em estado virtual que escapam às linhas mais sedimentadas do dispositivo da sustentabilidade pode ser um exercício importante para produzir desvios e criações neste dispositivo. Ana Godoy argumenta ser interessante forçar pensamentos sobre a vida por meio da arte e, portanto, "[...] estimular a invençâo e a transfiguração contra a apatia, o sossego e a tranquilidade alimentados pela vontade de verdade" (GODOY, 2008, p. 301), pela vontade, destacamos, de planificação e monetarização da vida.

Expandir, forçar, multiplicar, potencializar a vida, e as infinitas e plurais relaçôes socioambientais tecidas por diferentes coletivos (humanos e não humanos). Nos interstícios, nas porosidades, nas frestas das linhas imperiais do mercado que insistem em colonizar, "esverdear" e planificar sustentavelmente nossas vidas; quem sabe, alocar uma Educação Ambiental que teime em criar pensamentos, imagens, práticas repletas do desejo de tornarem vivas e potentes todas as formas não monetárias de vida.

\section{REFERÊNCIAS}

ACSELRAD, Henri. Discursos da sustentabilidade urbana. Revista Brasileira de Estudos Urbanos e Regionais. Campinas, n. 1, p. 79-90, maio de 1999.

DELEUZE, Gilles. ¿Qué es un dispositivo? In: BARBIER, E. et al. Michel Foucault, filósofo. Tradução de Alberto Bixio. Barcelona: Gedisa, 1999.

FERRAÇO, Carlos Eduardo. Pesquisa com o cotidiano. Educação e Sociedade, Campinas, v. 28, n. 98, p. 73-95, jan./abr. 2007.

FISCHER, Rosa Maria Bueno. O dispositivo pedagógico da mídia: modos de educar na (e pela) TV. Educação e Pesquisa, São Paulo, v. 28, n. 1, p. 151162, jan./jun. 2002.

FOUCAULT, Michel. Sobre a história da sexualidade. In: FOUCAULT, Michel. Microfísica do poder. Introdução, organização e tradução Roberto Machado. 18. ed. Rio de Janeiro: Graal, 2003.

GODOY, Ana. A menor das ecologias. São Paulo: Edusp, 2008.

HALL, Stuart. A centralidade da cultura: notas sobre as revoluçóes culturais do nosso tempo. Tradução de Ricardo Uebel, Maria Isabel Bujes e Marisa Vorraber Costa. Educação \& Realidade, Porto Alegre, v. 22, n. 2, p. 15-46, jul./dez. 1997. 
MARCELLO, Fabiana de Amorim. Sobre os modos de produzir sujeitos e práticas na cultura: o conceito de dispositivo em questão. Currículo sem Fronteiras, v. 9, p. 226-241, 2009.

MARCELLO, Fabiana de Amorim. Enunciar-se, organizar-se, controlarse: modos de subjetivação feminina no dispositivo da maternidade. Revista Brasileira de Educação, Rio de Janeiro, v. 29, p. 139-151, maio/ago. 2005.

MARCELLO, Fabiana de Amorim. O conceito de dispositivo em Foucault: mídia e produção agonística de sujeitos-maternos. Educação e Realidade, Porto Alegre, v. 29, n. 1, p.199-213, jan./jun. 2004.

REDCLIFT, Michael R. Sustainable development (1987-2005): an oxymoron comes of age. Horizontes Antropológicos, Porto Alegre, ano 12, n. 25, p. 65-84, jan./jun. 2006.

VEIGA-NETO, Alfredo. Foucault e a Educação. Belo Horizonte: Autêntica, 2005.

WILLIAMS, Raymond. Cultura \& Sociedade: 1780-1950. Tradução de Leônidas H. B. Hegenberg, Octanny Silveira da Mota e Anísio Teixeira. São Paulo: Editora Nacional, 1969. 


\section{El dispositivo de la sostenibi- The dispositif of sustaina- lidad: pedagogías en lo bility: contemporary contemporáneo pedagogies}

\section{Resumen}

Este trabajo se deriva de dos investigaciones cuyo foco central es la relación entre educación y sostenibilidad. En este texto, se discuten las pedagogías que circulan en la cultura a partir del dispositivo de sostenibilidad, a través de sus innumerables vehículos (textos periodísticos, tapas de revistas, entre otros). Inicialmente, se explica el concepto de dispositivo: noción con la cual se operan los análisis de las investigaciones. Luego, se profundiza en las pedagogías instituidas por las líneas de composición de este dispositivo de sostenibilidad a través de dos imágenes mediáticas sobre la problemática ambiental. A partir de estas imágenes, se argumenta sobre uno de los efectos pedagógicos del dispositivo: su penetrabilidad en los tejidos del mercado, en el modo como se ve y se narra la vida. Los referentes teóricos utilizados provienen de estudios culturales en sus vertientes post-estructuralistas. Este amplio y controvertido campo de estudio y de prácticas permite colocar borradura en las narrativas sobre sostenibilidad, buscando verlas en sus efectos.

Palabras clave: Sostenibilidad. Educación Ambiental. Educación por los Medios de Comunicación.

\section{Abstract}

This paper is derived from two studies that focus on the relationship between education and sustainability. It discusses pedagogies that circulate in the culture based on the dispositif of sustainability, through its numerous artifacts (newspaper articles, magazine covers, among others). The paper first explains the concept of dispositif that was used to conduct the studies. Second, the pedagogies established by the lines of composition of the dispositif of sustainability are contemplated through the analysis of two media images about the environmental issue. From them, it presents the educational effects of this dispositif, its penetrability through the webs of the market and the ways in which life is seen and narrated. The theoretical framework used here derives from cultural studies, in a post-structuralist orientation. This broad and controversial field of study and practice allows placing narratives about sustainability sob rasura to see them through their effects.

Keywords: Sustainability. Environmental Education. Education through Media. 
Shaula Maíra Vicentini de Sampaio

E-mail: shaula.maira@gmail.com

Leandro Belinaso Guimarães

E-mail: lebelinaso@uol.com.br

Recebido em: 10/3/2012

Versão final recebida em: 11/6/2012

Aprovado em: 12/6/2012 